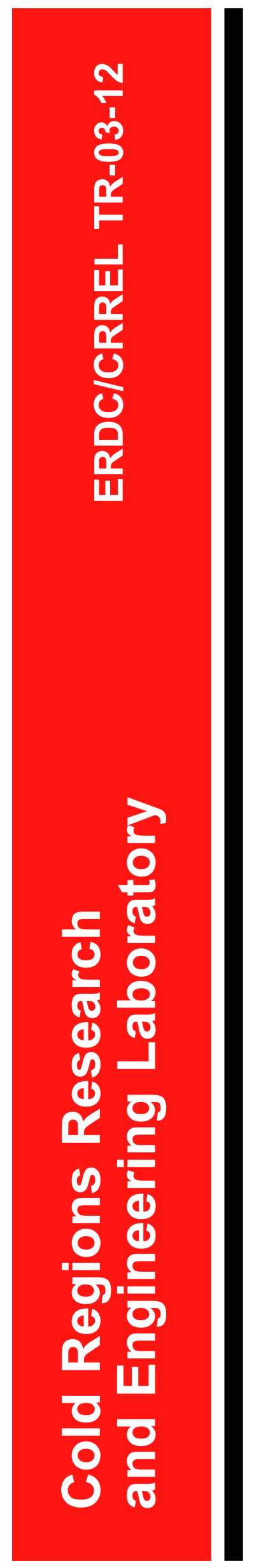

\title{
Diffusion and Flux of Explosive-Related Compounds in Plastic Mine Surrogates
}

James H. Cragin and Daniel C. Leggett

July 2003 


\title{
Diffusion and Flux of Explosive-Related Compounds in Plastic Mine Surrogates
}

\author{
James H. Cragin and Daniel C. Leggett \\ Cold Regions Research and Engineering Laboratory \\ 72 Lyme Road \\ Hanover, New Hampshire 03755
}

Approved for public release; distribution is unlimited. 


\section{ABSTRACT}

Canine detection of buried landmines is thought to be an olfactory process and efforts are now underway to develop electronic sensing of explosives vapors. The quantity of these vapors is critical to any chemical-sensing-based procedure for detecting landmines. Plastic-cased mines release vapors of explosive-related compounds (ERC) by permeation through the casing as well as through holes and cracks. Measurement of permeation contributions to the release flux was reported previously for a few intact mines. Here we determine permeation-driven fluxes and diffusivities by analysis of ERC release into water as a function of time. The solubility of TNT and diffusivities of TNT, 2,4-DNT, and 1,3-DNB in five polymeric materials potentially used in mine casings are reported for the first time. This information can be used to estimate ERC fluxes from TNT-filled mines encased in any of these materials. Direct measurement of the release fluxes from intact mines are feasible and were described previously. Calculated diffusivities of the nitroaromatics in these materials were similar to those reported in the literature for other aromatic vapors. Diffusion was generally non-Fickian (concentration-dependent). TNT fluxes into Tedlar bags were also measured at 3,13 , and $22^{\circ} \mathrm{C}$ for the five materials. The temperature dependence is well described by simple exponential relations of the van't Hoff/Arrhenius type, and an activation energy was calculated for the process. The temperature dependence of the fluxes was similar for all five materials. Fluxes of individual ERC components were also determined at $22^{\circ} \mathrm{C}$ and reflected their abundance in the headspace of the source explosive. Plastic/air partition coefficients of the contaminants ranged from $1 \times 10^{3}$ to $3 \times 10^{5}$ and were about an order of magnitude higher for TNT than for DNB and were intermediate for DNT.

DISCLAIMER: The contents of this report are not to be used for advertising, publication, or promotional purposes. Citation of trade names does not constitute an official endorsement or approval of the use of such commercial products. All product names and trademarks cited are the property of their respective owners. The findings of this report are not to be construed as an official Department of the Army position unless so designated by other authorized documents. 


\section{CONTENTS}

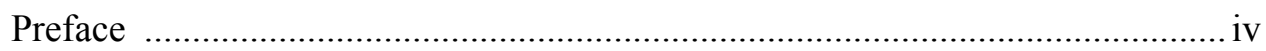

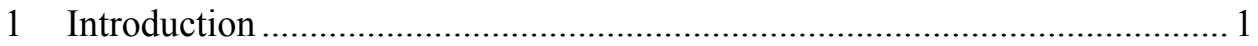

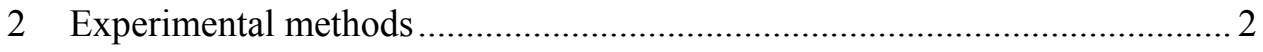

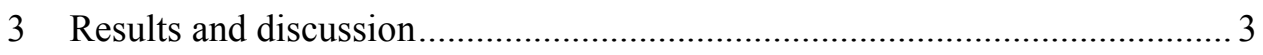

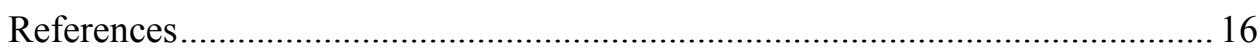

\section{ILLUSTRATIONS}

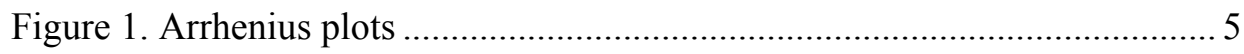

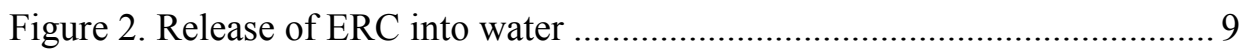

Figure 3. $t^{1 / 2}$ plot of ERC release vs. the square root of time............................ 13

\section{TABLES}

Table 1. Fluxes of TNT from plastic surrogates as a function of temperature .... 4

Table 2. Activation energies for diffusive flux of TNT in polymers .................. 7

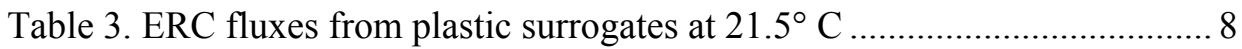

Table 4. Solubilities and plastic/air partition coefficients of ERC from

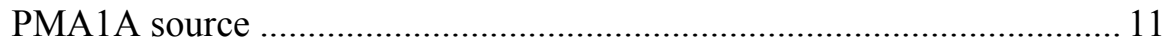

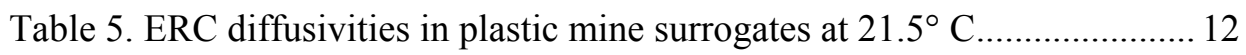

Table 6. Some diffusivities from the literature ................................................ 15 


\section{PREFACE}

This report was prepared by James H. Cragin, Research Chemist, Snow and Ice Branch, Engineer Research and Development Center (ERDC), U.S. Army Cold Regions Research and Engineering Laboratory (CRREL), Hanover, New Hampshire; and by Daniel C. Leggett, Research Chemist, Environmental Sciences Branch, ERDC-CRREL.

This work was sponsored by the Defense Advanced Research Projects Agency (DARPA), Regina Dugan, Program Manager; Vivian George was the Project Monitor. Technical review of this work was provided by Dr. James M. Phelan, Sandia National Laboratories, and Marianne E. Walsh, CRREL.

The Commander and Executive Director of the Engineer Research and Development Center is COL John W. Morris III, EN. The Director is Dr. James R. Houston. 


\title{
Diffusion and Flux of Explosive-Related Compounds in Plastic Mine Surrogates
}

\author{
JAMES H. CRAGIN AND DANIEL C. LEGGETT
}

\section{INTRODUCTION}

Trinitrotoluene (TNT) explosives worldwide are known to emit vapors of TNT, DNT, and DNB isomers (Leggett et al. 1977, Jenkins et al. 2000). These same vapors are also emitted by intact mines (Leggett et al. 2001) and contaminate their surfaces (Leggett et al. 2000). Vapor-contaminated materials, themselves, remain a source of vapors for many days (Bender et al. 1992). These emitted vapors are sorbed and concentrated on soil around buried landmines (George et al. 1999). The success with which canines locate buried landmines suggests an olfactory process: chemical sensing of airborne vapors or vaporcontaminated particles. Efforts are now under way to develop electronic sensors for these vapors.

Plastic mine casings are prevalent and are expected to attenuate the strength of the vapor source of the charge. Moreover, the various plastics that are used to fabricate mine casings are expected to have different permeabilities, dependant on the individual solubility and diffusivity of the explosive-related compound (ERC) emitted by the source. If the solubility and diffusivity of a compound are known, one can calculate a flux as $F=D \times S / L$, where $L$ is the thickness of the casing. ERC solubilities and diffusivities were not available in the literature, however, so these measurements are reported here for five common plastic materials potentially used for fabricating mine casings. The effect of temperature on release of ERC into air was also studied, as was the release into water as a function of time. The latter data were used to calculate diffusivities.

At the time this work was proposed, we did not know that it would be possible to measure ERC fluxes from landmines directly. While the present work was being conducted, we also succeeded in performing flux measurements on a number of intact landmines using these same methods. That work is reported elsewhere (Leggett et al. 2001), and the two studies are complementary and form a more complete picture. 


\section{EXPERIMENTAL METHODS}

Mine-casing surrogates were made from one-eighth-inch-thick $(0.32-\mathrm{cm})$ sheets of low- and high-density polyethylene, polypropylene, polystyrene, and polyvinyl chloride (LDPE, HDPE, PP, PS, PVC) (AIN Plastics, Mount Vernon, New York). Circular sections $7.4 \mathrm{~cm}$ in diameter were cut from these to use in experiments. These surrogates were then placed in a glass desiccator jar with the main charge (200-g block of TNT) from a PMA1A landmine and maintained at $22^{\circ} \mathrm{C}$ for six months. An initial study was done using as a source $\sim 100 \mathrm{mg}$ of TNT scraped from the surface of a PMA1A charge, but the results were partly in error because the specimens were undersaturated in DNT and DNBs. Evidently the source had been depleted of volatiles before the specimens were saturated. TNT saturation was unaffected, however, as shown by later experiments, so these data were used to estimate the temperature dependence of the TNT flux.

Tedlar bags (Norton), $15 \times 15 \mathrm{~cm}(6 \times 6$ in. $)$, were purchased from Fisher Scientific. One end was cut off so the plastic disk could be inserted. The bags were sealed with plastic crimp seals from $\mathrm{I}^{2} \mathrm{R}$. The enclosed specimens were then placed in a dark temperature-controlled room at $21.5^{\circ} \mathrm{C}$ for seven days, when the bag was opened and the disk removed. Ten $\mathrm{mL}$ of acetonitrile (HPLC-grade, Burdick and Jackson) was added and the bag reclosed with the crimp seals. The solvent was allowed to briefly rinse all internal surfaces of the bag, decanted into a vial, and $1 \mathrm{~mL}$ removed for analysis.

For water collection, plastic surrogates were submerged individually in an appropriate volume of MilliQ water in a silanized glass jar. The setup was agitated gently on a platform shaker in a dark room controlled at $21.5^{\circ} \mathrm{C}$. Three-mL water samples were taken periodically for analysis. These experiments were continued until the water concentrations approached equilibrium, about two months.

Water and acetonitrile extracts were analyzed by HPLC-UV. Standard Analytical Reference Materials (SARMs) for 1,3-dinitrobenzene (DNB), 2,4dinitrotoluene (DNT), 2,4,6-trinitrotoluene (TNT), and hexahydro-1,3,5-trinitro1,3,5-triazine (RDX) were obtained from Army Environmental Center, Edgewood, Maryland. A working stock containing $1.0 \mathrm{mg} / \mathrm{L}$ of each analyte in acetonitrile was prepared. Water samples were diluted with one part acetonitrile, and acetonitrile extracts and stock standards were diluted with three parts MilliQ water. All samples and standards were filtered through 0.45-micron Durapore (Waters) membrane syringe (B-D) filters prior to analysis. A 10-cm HPLC column (NovaPak $\mathrm{C}_{8}$ ) was used to separate the analytes using water:isopropanol $(16: 3)$ as the mobile phase at a flow rate of $1.4 \mathrm{~mL} / \mathrm{min}$. 


\section{RESULTS AND DISCUSSION}

Originally we had intended to conduct typical breakthrough experiments involving a vapor source on one side of a plastic sheet and collection of the permeate on the other. This would also simulate an explosive charge with a mine casing barrier. However, as a result of some experimental and practical difficulties, we later abandoned this approach and adopted the methodology described above. At the outset we also were not aware that we would be able to measure fluxes directly from landmines. While the present work was in progress we succeeded in measuring ERC fluxes from several types of intact landmines (Leggett et al. 2001).

One set of five plastic mine surrogates was equilibrated for several months in a tightly closed jar with $\sim 100 \mathrm{mg}$ of TNT scraped from a PMA1A source. The specimens were then placed in Tedlar bags for one week, removed, and the ERC residues extracted from the bags. Very low concentrations of DNT and DNB were found relative to their concentrations in equilibrium headspace, or in similar experiments with intact landmines. This caused us to surmise that the source, because of its small size, had become depleted in these more volatile compounds before saturation of the plastic specimens was complete. In any case, these specimens were still used for flux measurements at three temperatures, but only the fluxes of TNT are reported (Table 1).

The flux vs. temperature data are plotted as $\ln F$ vs. 1/T in Figure 1a-e. This is the familiar Arrhenius Law plot, in which the slope of the line is directly related to an activation energy for the flux. It may also be interpreted as an activation energy for diffusion since they are linearly related through the equation (Park et al. 1996)

$$
F=D \times S / L
$$

where $D$ is the diffusion coefficient in $\mathrm{cm}^{2} / \mathrm{s}, S$ is solubility or concentration in the polymer in $\mathrm{g} / \mathrm{cm}^{3}$, and $L$ is the thickness of the specimen in $\mathrm{cm}$. Good fits were obtained in all cases. The activation energies presented in Table 2 are derived from the fit to an Arhennius equation:

$$
F=\mathrm{F}_{\mathrm{o}} \times \mathrm{e}^{-\mathrm{E} / \mathrm{RT}}
$$

where $\mathrm{F}_{\mathrm{o}}$ is a constant, $E$ is an activation energy, $\mathrm{R}$ is the gas constant, and $T$ is absolute temperature. The linearized form 


$$
\ln F=\ln \mathrm{F}_{\mathrm{o}}-E / \mathrm{R} T
$$

was used to analyze the data by linear regression (StatView). The derived activation energies for diffusive flux are remarkably similar for four of the five materials. PVC is also similar if one discounts one of the data points.

\begin{tabular}{|c|c|c|}
\hline Plastic & $\begin{array}{c}\mathrm{T} \\
\left({ }^{\circ} \mathrm{C}\right)\end{array}$ & $\underset{\left.\mathrm{fg} / \mathrm{cm}^{2} \mathrm{~s}\right)}{\text { Flux }}$ \\
\hline \multirow[t]{3}{*}{ HDPE } & -4.0 & 5.8 \\
\hline & 9.2 & 33.6 \\
\hline & 21.5 & 115 \\
\hline \multirow[t]{3}{*}{ LDPE } & -4.0 & 13.5 \\
\hline & 9.2 & 46.4 \\
\hline & 21.5 & 253 \\
\hline \multirow[t]{3}{*}{ PP } & -4.0 & 9.2 \\
\hline & 9.2 & 54.1 \\
\hline & 21.5 & 158 \\
\hline \multirow[t]{3}{*}{ PS } & -4.0 & 13.8 \\
\hline & 9.2 & 86.9 \\
\hline & 21.5 & 270 \\
\hline \multirow[t]{3}{*}{ PVC } & -4.0 & 4.7 \\
\hline & 9.2 & 23.2 \\
\hline & 21.5 & 46.2 \\
\hline
\end{tabular}

The apparent uniformity of diffusion energetics in even four or five different polymer materials is remarkable considering that PS is aromatic and polarizable, and PVC is polar (Paley et al. 1990); both might be expected to have a stronger affinity for TNT than the non-aromatic, weakly polarizable PE and PP. This suggests to us that the interaction of TNT with these polymers is nonspecific and results primarily from dispersion forces. This is consistent with linear free energy analysis of partitioning of nitroaromatics and other solutes between PVC, PTFE (Teflon), and water (Leggett and Parker 1994). There are few data with which to compare the data of Table 2. The estimated activation energy of TNT diffusion in nitrile butadiene rubber is $30-35 \mathrm{~kJ} /$ mole at $93-113^{\circ} \mathrm{C}$ (Tung et al. 1997). However, TNT diffusivity in that work was two orders of magnitude greater than in the materials studied here and the temperature range much higher, so a factor-oftwo difference in activation energy does not appear to be inconsistent with our 
data. The heat of sublimation of TNT, in effect its self-interaction, is $99 \mathrm{~kJ} / \mathrm{mole}$ (Pella 1976). Again, this fact supports the relatively weak interaction between TNT and these polymers. From the conformity of the temperature dependence of DNB and DNT fluxes from intact landmines (Leggett et al. 2001) with that reported here we can extend the weak interaction inference to these other ERC as well.

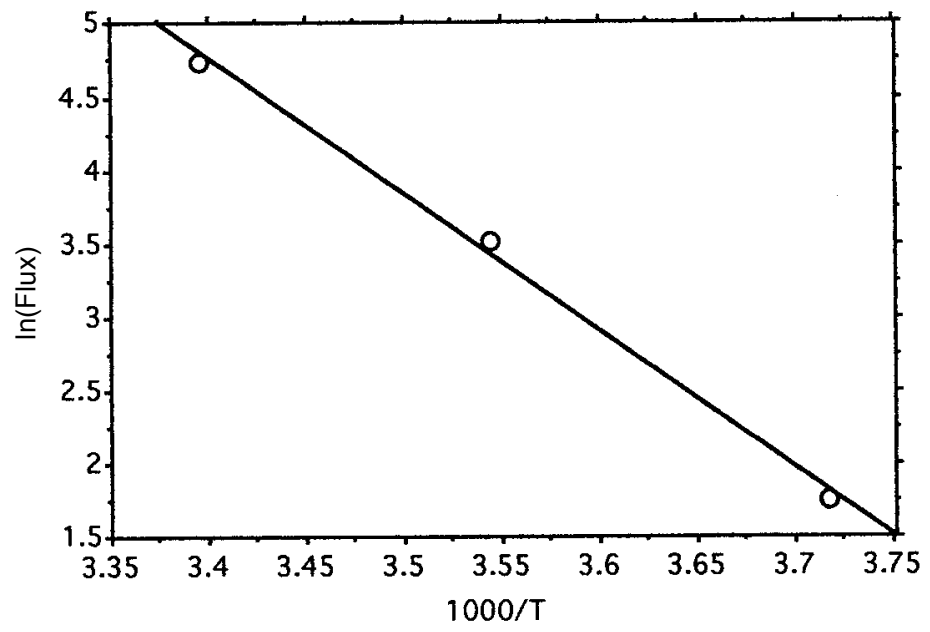

a. TNT flux from HDPE.

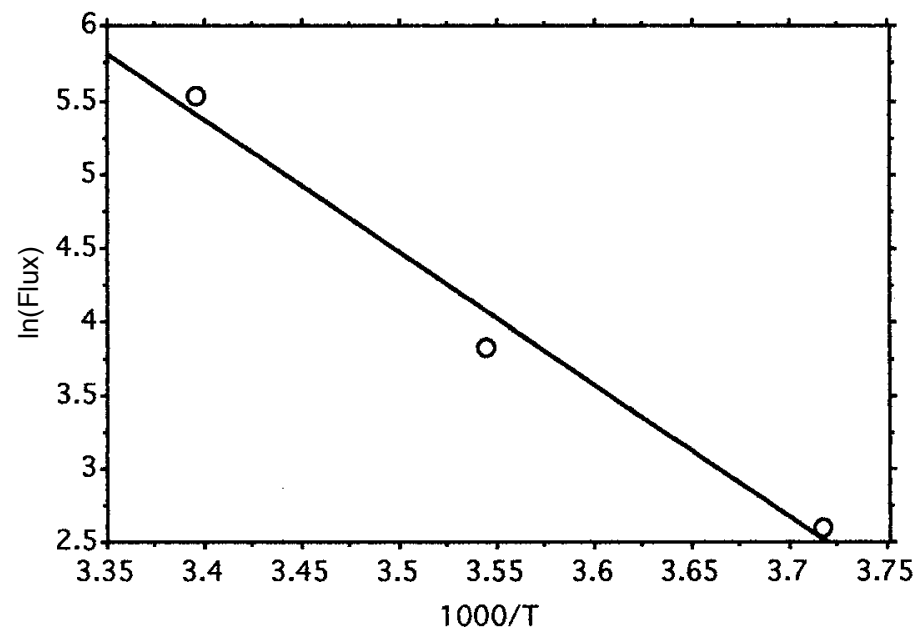

b. TNT flux from LDPE.

Figure 1. Arrhenius plots. 


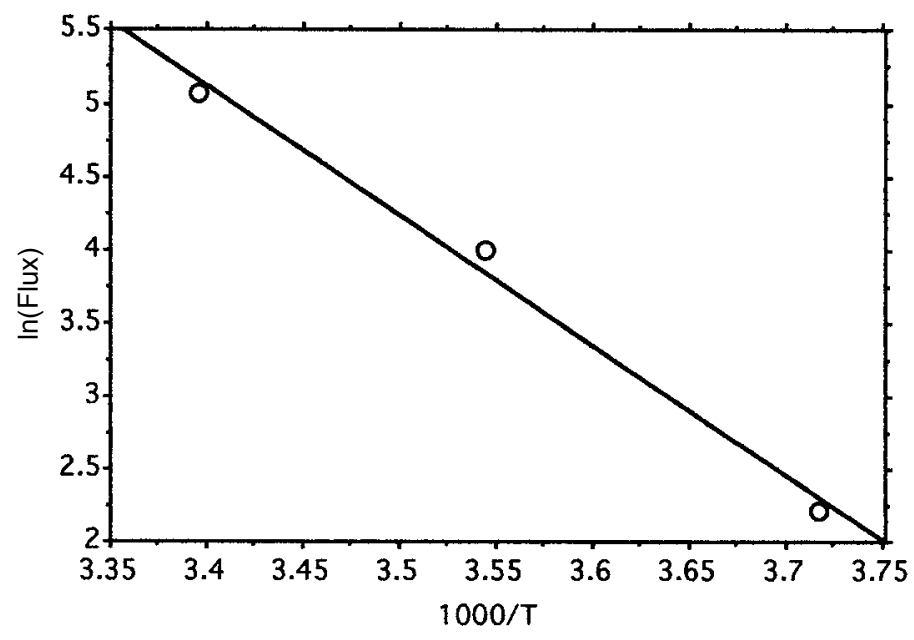

c. TNT flux from PP.

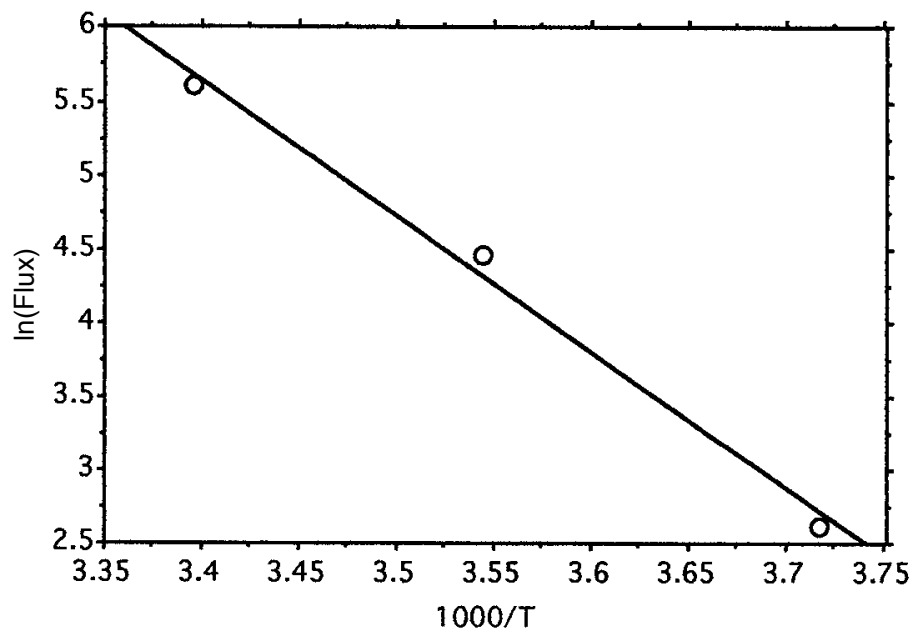

d. TNT flux from PS.

Figure 1 (cont'd). Arrhenius plots. 


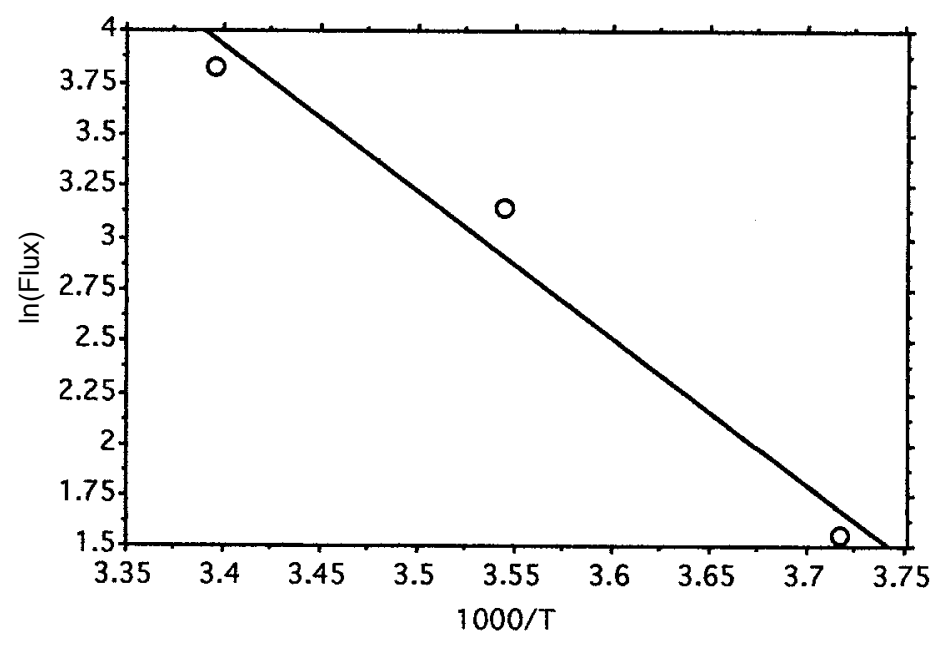

e. TNT flux from PVC.

Figure 1 (cont'd).

\begin{tabular}{|c|c|}
\hline $\begin{array}{l}\text { Table 2. Activation energies for diffusive flux of TNT in } \\
\text { polymers. }\end{array}$ \\
\hline Plastic & $\begin{array}{c}\text { E } \\
\text { (kJ/mole) }\end{array}$ \\
\hline HDPE & 77.7 \\
\hline LDPE & 75.4 \\
\hline PP & 74.2 \\
\hline PS & 77.4 \\
\hline PVC & $59.5\left(76.3^{\star}\right)$ \\
\hline${ }^{*}$ Without $21.5^{\circ} \mathrm{C}$ point. \\
\hline
\end{tabular}

A second set of plastic surrogates like the first were equilibrated with a $200-\mathrm{g}$ block of TNT from a PMA1A mine for six months at $22^{\circ} \mathrm{C}$. The specimens were then bagged in Tedlar for one week at $21.5^{\circ} \mathrm{C}$. The collected vapors were analyzed as before and converted to fluxes of DNB, DNT, and TNT shown in Table 3. The TNT fluxes should be and are similar to the first, as expected (Table 1). The DNB and DNT fluxes are now also consistent with their concentrations in the headspace vapor and fluxes from intact mines reported elsewhere (Leggett et al. 2001). 


\begin{tabular}{|c|c|c|c|}
\hline \multicolumn{4}{|c|}{ Table 3. ERC fluxes $\mathbf{( f g / \mathbf { c m } ^ { 2 }} \mathbf{s}$ ) from plastic surrogates at $\mathbf{2 1 . 5}^{\circ} \mathbf{C}$. } \\
\hline Plastic & DNB & DNT & TNT \\
\hline LDPE & 1900 & 600 & 225 \\
\hline HDPE & 906 & 367 & 144 \\
\hline PP & 1520 & 521 & 200 \\
\hline PS & 1230 & 394 & 217 \\
\hline PVC & 231 & 87 & 59 \\
\hline
\end{tabular}

Following this experiment the plastic surrogates were placed in jars containing $100 \mathrm{~mL}$ of water and the solutions analyzed periodically for two months. Desorption curves for TNT, DNT, and DNB from the five TNT-saturated plastics in water are shown in Figures 2a-e. Following desorption in water the specimens were transferred to $10.0 \mathrm{~mL}$ of acetonitrile and extracted for two weeks. From analysis of the acetonitrile extracts, the water, and the Tedlar bags, a total mass and solubility were obtained for each compound of interest. The mass/volume solubilities were determined by dividing these masses by $13.66 \mathrm{~cm}^{3}$, the computed volume of the individual specimens. Plastic/air partition coefficients, $\mathrm{K}_{\mathrm{pa}}$, were calculated as $S$ divided by the equilibrium vapor concentration in the headspace over the source. $S$ and $\mathrm{K}_{\mathrm{pa}}$ for TNT, DNT, and DNB in the five materials are presented in Table 4.

A standard way of determining diffusion coefficients is from mass uptake with time experiments (Berens and Hopfenberg 1982, Ogawa and Masuichi 1997). Here we have measured mass loss with time and apply a similar analysis since diffusion is assumed to be reversible. For Fickian diffusion D is constant and the rate of mass gain or loss should be proportional to the square root of time according to the following equation (Ogawa and Masuichi 1997):

$$
m_{\mathrm{t}} / S=4\left(\mathrm{D} \times \mathrm{t} / \pi \times d^{2}\right)^{1 / 2}
$$

where $m_{\mathrm{t}}$ is mass change at time $t, S$ is total mass gain at saturation, i.e., solubility, $\mathrm{D}$ is the diffusion coefficient, and $d$ is the thickness of the material specimen $(0.3175 \mathrm{~cm})$. Thus a plot of $m_{\mathrm{t}} / S$ vs. $t^{1 / 2}$ will yield the diffusion coefficient as the slope of this line squared times 0.0198 .

The desorption histories of the specimens are replotted as fractional mass lost vs. $t^{1 / 2}$ as a continuum to include both the air and water experiments (Fig. 3a-e). The initial mass lost in air $\left(t^{1 / 2}<2.65\right.$ days $\left.^{1 / 2}\right)$ was followed by a more rapid decline when the specimens were first placed in water. We believe the slower initial loss in air is due to mass transport limitation in air relative to water, which 
is a function of large plastic/air partition coefficients $\left(\mathrm{K}_{\mathrm{pa}}>10^{3}\right.$; Table 4). This phenomenon was observed previously in the flux measurements using actual mines (Leggett et al. 2001). Following the initially more rapid loss in water, the rate of mass loss slows, indicating diffusion of the ERC in these materials is nonFickian, and there are no unique, concentration-independent diffusivities.

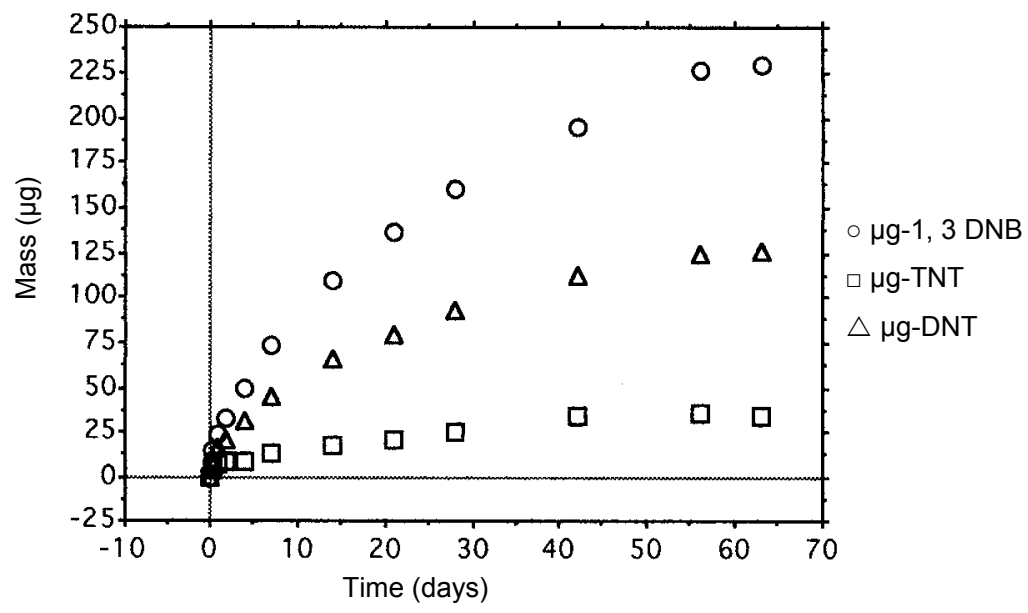

a. From HDPE.

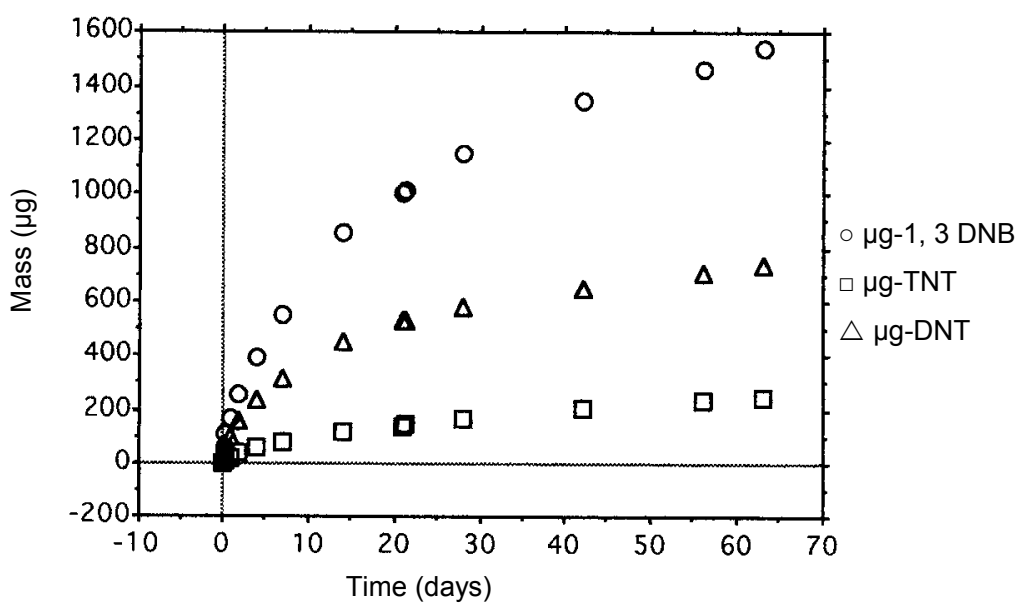

b. From LDPE.

Figure 2. Release of ERC into water. 


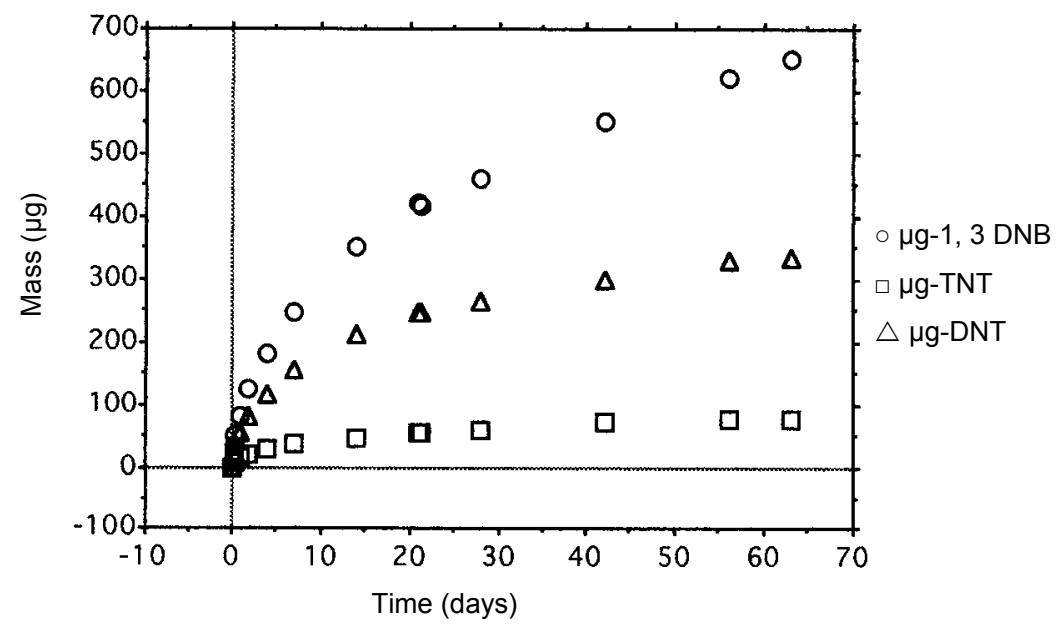

c. From PP.

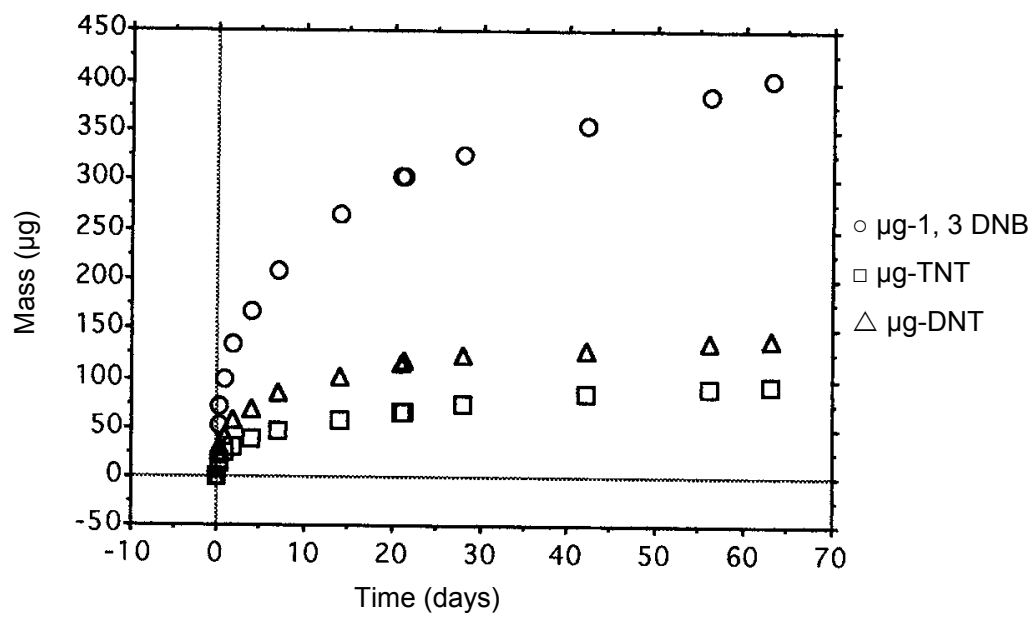

d. From PS.

Figure 2 (cont'd). Release of ERC into water. 


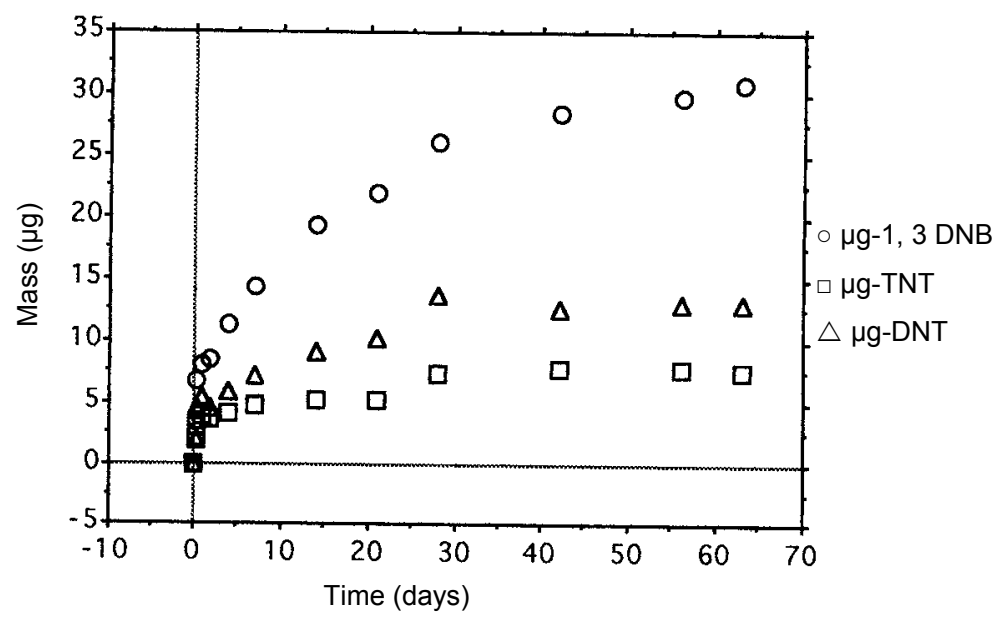

e. From PVC.

Figure 2 (cont'd).

\begin{tabular}{|c|c|c|c|c|c|c|}
\hline \multicolumn{3}{|c|}{ DNB } & \multicolumn{2}{|c|}{ DNT } & \multicolumn{2}{|c|}{ TNT } \\
\hline Plastic & $\mathrm{S}^{*}$ & $\mathrm{~K}_{\mathrm{pa}}^{\dagger}$ & $S$ & $\mathrm{~K}_{\mathrm{pa}}$ & $S$ & $\mathrm{~K}_{\mathrm{pa}}$ \\
\hline HDPE & 23.1 & 5 & 12.6 & 9 & 3.64 & 47 \\
\hline LDPE & 137 & 3 & 75.7 & 54 & 22.4 & 290 \\
\hline PP & 60.1 & 13 & 31.5 & 23 & 7.2 & 92 \\
\hline PS & 72 & 16 & 24.6 & 18 & 15.2 & 190 \\
\hline PVC & 5.14 & 1.1 & 1.87 & 1.3 & 1.15 & 15 \\
\hline \multicolumn{7}{|c|}{$\begin{array}{l}{ }^{*} \mathrm{~S} \text { in } \mathrm{g} / \mathrm{cm}^{3} \times 10^{6} \\
{ }^{+} \mathrm{K}_{\mathrm{pa}} \text { in } \mathrm{V}_{\text {air }} / \mathrm{V}_{\text {plastic }} \times 10^{-3}\end{array}$} \\
\hline
\end{tabular}

The diffusion coefficients presented in Table 5 were determined by least squares analysis of the desorption curves at less than about $60 \%$ of saturation, where they appear to be more nearly Fickian. Good agreement was in any case obtained between these data and published diffusivities of other aromatic compounds in plasticized materials or unplasticized materials above their glass transition temperatures (Table 6). Plasticization essentially involves addition of a semi-volatile solvent during the manufacture, which effectively lowers the overall glass transition temperature of the plastic. The work of Berens and Hopfenberg (1982) (Table 6) and others (Romdhane et al. 1995) clearly shows diffusion of many compounds in unplasticized polyvinyl chloride or polystyrene powders to be several orders of magnitude slower than observed here. Thus one 
can infer that the materials we used here have glass transitions below room temperature either naturally (PE, PP) or by addition of plasticizers (PVC, PS). Comparison with flux values presented earlier (Leggett et al. 2001) suggests that actual mine casing materials also have glass transitions below room temperature.

Table 5. ERC diffusivities $\left(\mathrm{cm}^{2} / \mathrm{s} \times 10^{10}\right)$ in plastic mine surrogates at $21.5^{\circ} \mathrm{C}$.

\begin{tabular}{|c|c|c|c|}
\hline Plastic & DNB & DNT & TNT \\
\hline HDPE & 30 & 28 & 28 \\
\hline LDPE & 22 & 12 & 30 \\
\hline PP & 21 & 13 & 15 \\
\hline PS & 2.3 & 1.1 & 4 \\
\hline PVC & 4 & 4 & 6 \\
\hline PS-PMA2* & 1.3 & 0.66 & 2.9 \\
\hline * From steady-state flux in Water (Leggett et al. 2001). \\
\hline
\end{tabular}

Also included in Table 5 are calculated diffusivities for TNT, DNT, and DNB in an intact PMA2 landmine casing using

$$
D=F \times L / S .
$$

$S$ was measured by extracting ERC from a PMA2 casing with acetonitrile, and their fluxes in water at steady state were from a different intact mine (Leggett et al. 2001). Tests indicated that the casing is 2-mm-thick polystyrene. Good agreement was obtained between the diffusivities in the casing compared to the surrogate. Accurate prediction of ERC fluxes from landmines, however, is more problematic because a number of factors will have a greater influence than the diffusivities.

Apparent solubilities or concentrations of volatile TNT impurities, including DNT and DNB, in TNT-filled mine casings will be a function of their abundance in the source charge, which varies considerably from manufacturer to manufacturer (Leggett et al. 1977, Jenkins et al. 2001). The presence of varying quantities of plasticizers and other additives in actual casing materials may also affect contaminant transport properties. Further, release of ERC from intact landmines to air appears to be retarded by mass transport resistance (Leggett et al. 2001), as it was with surrogates, so that fluxes are under mass transport control rather than diffusion limited. Initial measurements of landmine fluxes in dry sand were comparable to those in air, while moist sand significantly retarded the experimental 
fluxes, contrary to expectation (Leggett and Cragin, unpublished data). The best approach will be to measure landmine fluxes directly under conditions simulating their deployment.

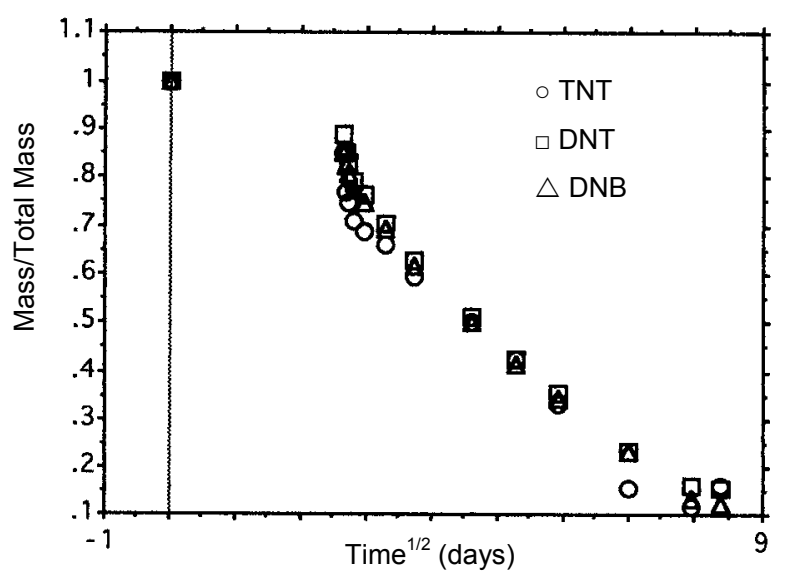

a. From HDPE.

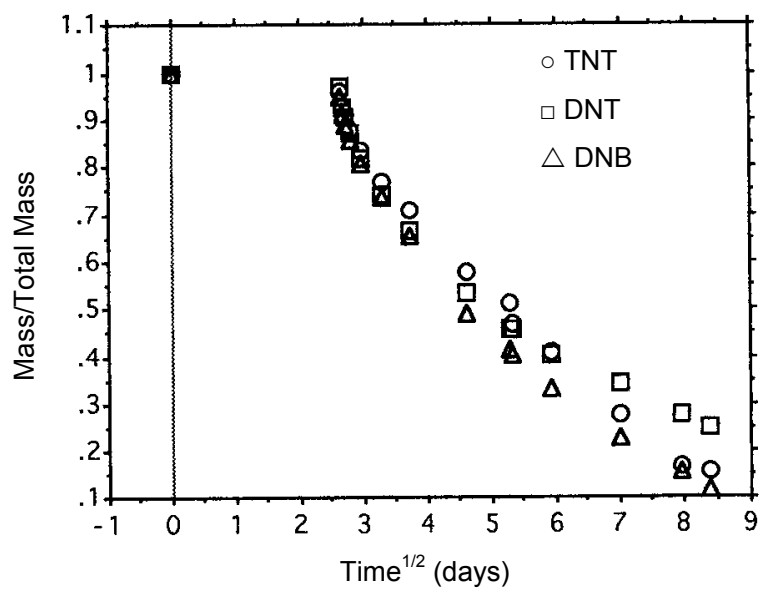

b. From LDPE.

Figure 3. $t^{1 / 2}$ plot of ERC release vs. the square root of time. 


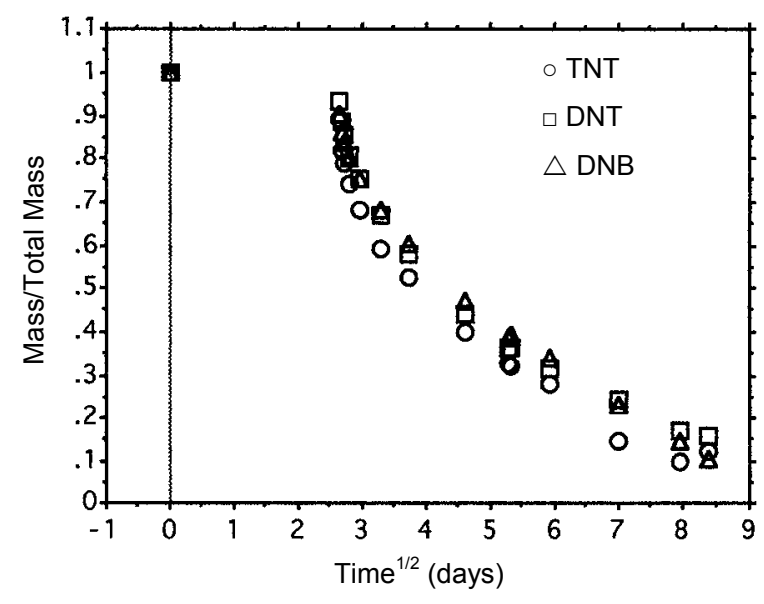

c. From PP.

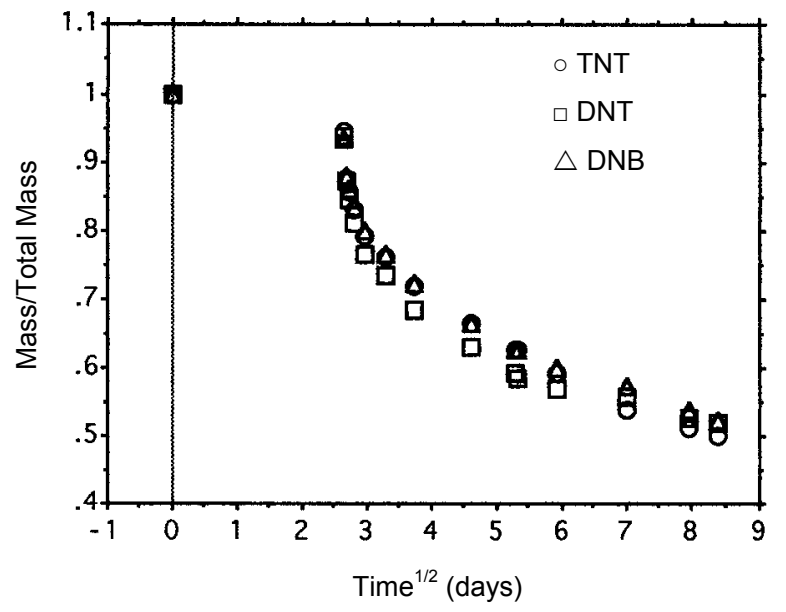

d. From PS.

Figure 3 (cont'd). $t^{1 / 2}$ plot of ERC release vs. the square root of time. 


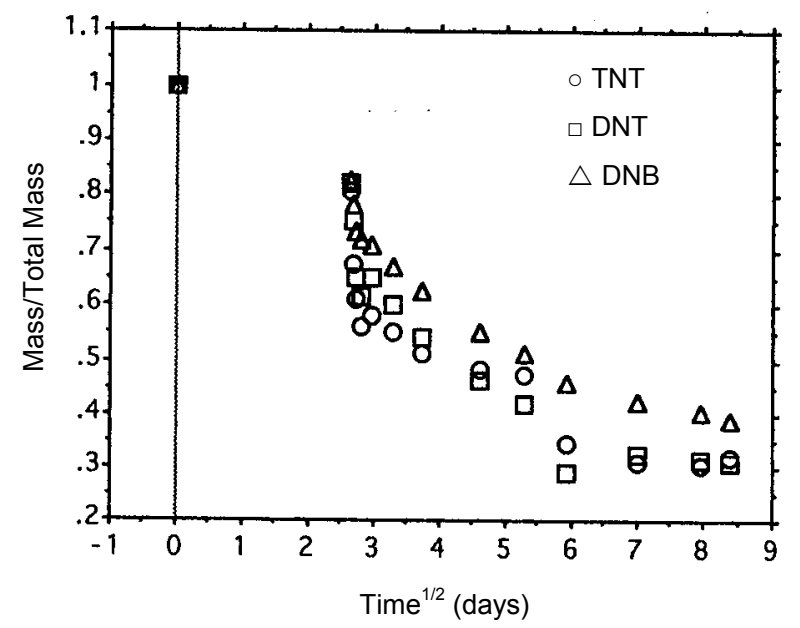

e. From PVC.

Figure 3 (cont'd).

\begin{tabular}{|c|c|c|c|c|}
\hline \multicolumn{5}{|c|}{ Table 6. Some diffusivities $\left(\mathrm{cm}^{2} / \mathrm{s} \times 10^{10}\right)$ from the literature ${ }^{a}$. } \\
\hline Compound & HDPE & LDPE & PS & PVC \\
\hline Benzene & $51^{\mathrm{b}}$ & $79^{\mathrm{e}}$ & $0.005^{f}$ & $0.0002^{f}$ \\
\hline \multirow[t]{2}{*}{ Toluene } & $51^{\mathrm{C}}$ & $40^{\mathrm{e}}$ & & $54^{\mathrm{d}}$ \\
\hline & $32^{\mathrm{d}}$ & & & \\
\hline \multirow[t]{3}{*}{ Xylenes } & $33^{\mathrm{b}}$ & $10^{\mathrm{e}}$ & & $160^{d}$ \\
\hline & $10^{\mathrm{C}}$ & & & \\
\hline & $53^{d}$ & & & \\
\hline DEHP & & & & 1.2 \\
\hline $\mathrm{DNT}^{\mathrm{h}}$ & 28 & 12 & 1.1 & 4 \\
\hline \multicolumn{5}{|c|}{ From saturated vapor or aqueous solutions at $20-30^{\circ} \mathrm{C}$. } \\
\hline \multicolumn{5}{|c|}{ b Park and Nibras (1993). } \\
\hline \multicolumn{5}{|c|}{ Prasad et al. (1994). } \\
\hline \multicolumn{5}{|c|}{ d Reynolds et al. (1989). } \\
\hline \multicolumn{5}{|c|}{ e Reynolds et al. (1989). } \\
\hline \multicolumn{5}{|c|}{ Unplasticized material (Berens and Hopfenberg 1982). } \\
\hline \multicolumn{5}{|c|}{ g Diethylhexyl phthalate (Bichara et al. 1999). } \\
\hline \multicolumn{5}{|l|}{ h This work. } \\
\hline
\end{tabular}




\section{REFERENCES}

Bender, E., A. Hogan, D. Leggett, G. Miskolczy, and S. MacDonald (1992)

Surface contamination by TNT. Journal of Forensic Science, 37(6): 1673-1678.

Berens, A.R., and H.B. Hopfenberg (1982) Diffusion of organic vapors at low concentrations in glassy PVC, polystyrene, and PMMA. Journal of Membrane Science, 10: 283-303.

Bichara, A., J.-L. Fugit, and J.-L. Taverdet (1999) Modeling of mass transfers between food simulants and treated plasticized PVC. Journal of Applied Polymer Science, 72: 49-58.

George, V., T.F. Jenkins, D.C. Leggett, J.H. Cragin, J. Phelan, J. Oxley, and J. Pennington (1999) Progress on determining the vapor signature of a buried landmine. SPIE, Vol. 3710, 258-269.

Jenkins, T.F., M.E. Walsh, P.H. Miyares, J.A. Kopczynski, T.A. Ranney, V. George, J. Pennington, and T.E. Berry, Jr. (2000) Analysis of ExplosivesRelated Chemical Signatures in Soil Samples Collected near Buried Landmines. U.S. Army Cold Regions Research and Engineering Laboratory, Hanover, New Hampshire, ERDC/CRREL Technical Report TR-00-5.

Jenkins, T.F., D.C. Leggett, M.E. Walsh, P.H. Miyares, T.A. Ranney, J.H. Cragin, and V. George (2001) Chemical signatures of TNT-filled landmines. Talanta, 54: 501-513.

Leggett, D.C., and L.V. Parker (1994) Modeling the equilibrium partitioning of organic contaminants between PTFE, PVC, and groundwater. Environmental Science and Technology, 28(7): 1229-1233.

Leggett, D.C., T.F. Jenkins, and R.P. Murrmann (1977) Composition of Vapors Evolved from Military TNT as Influenced by Temperature, Solid Composition, Age, and Source. U.S. Army Cold Regions Research and Engineering Laboratory, Hanover, New Hampshire, Special Report 77-16.

Leggett, D.C., T.F. Jenkins, A.W. Hogan, T.A. Ranney, and P.H. Miyares (2000) External Contamination of Landmines by Organic Nitro-Compounds. U.S. Army Engineer Research and Development Center, ERDC/CRREL Technical Report TR-00-2.

Leggett, D.C., J.H. Cragin, T.F. Jenkins, and T.A. Ranney (2001) Release of Explosive-Related Vapors from Landmines. U.S. Army Engineer Research and Development Center, ERDC/CRREL Technical Report TR-01-6. 
Ogawa, T., and M. Masuichi (1997) Diffusion of organic solvents into polycarbonate film. Journal of Polymer Science, 63(7): 943-949.

Paley, M.S., R.A. McGill, S.C. Howard, S.E. Wallace, and J.M. Harris (1990) Solvatochromism: A new method for polymer characterization. Macromolecules, 23: 4557-4564.

Park, J.K., and M. Nibras (1993) Mass flux of organic chemicals through polyethylene geomembranes. Water Environment Research, 65: 227-237.

Park, J.K., J.P. Sakti, and J.A. Hoopes (1996) Transport of organic compounds in thermoplastic geomembranes. I: Mathematical Model. Journal of Environmental Engineering, 122(9): 800-806.

Pella, P. (1976) Generator for producing trace vapor concentrations of 2,4,6trinitrotoluene, 2,4-dinitrotoluene, and ethylene glycol dinitrate for calibrating explosives vapor detectors. Analytical Chemistry, 48(11): 1632-1637.

Prasad, T.V., K.W. Brown, and J.C. Thomas (1994) Diffusion coefficients of organics in high-density polyethylene (HDPE). Waste Management \& Research, 12: $61-71$.

Reynolds, G.W., J.T. Hoff, and R.W. Gillham (1989) Sampling bias caused by materials used to monitor halocarbons in groundwater. Environmental Science and Technology, 24(1): 135-142.

Romdhane, I.H., R.P. Danner, and J.L. Duda (1995) Influence of the glass transition on solute diffusion in polymers by inverse gas chromatography. Industrial and Engineering Chemistry Research, 34: 2833-2840.

Tung, Y.S., R. Mu, D.O. Henderson, and W.A. Curby (1997) Diffusion kinetics of TNT in acrylonitrile-butadiene rubber via FT-IR/ATR spectroscopy. Applied Spectroscopy, 51(2): 171-177. 


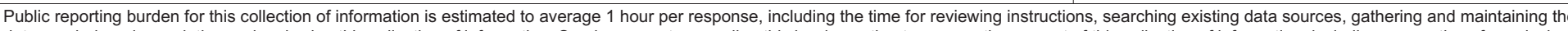

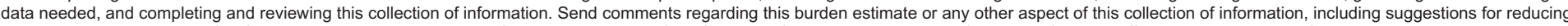

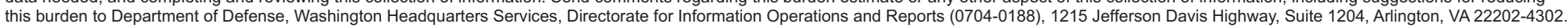

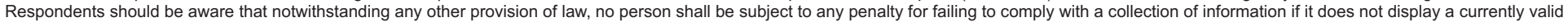
OMB control number. PLEASE DO NOT RETURN YOUR FORM TO THE ABOVE ADDRESS.
1. REPORT DATE (DD-MM-YY)
July 2003
2. REPORT TYPE
Technical Report

4. TITLE AND SUBTITLE

Diffusion and Flux of Explosive-Related

Compounds in Plastic Mine Surrogates

6. AUTHOR(S)

James H. Cragin and Daniel C. Leggett
3. DATES COVERED (From - To)

5a. CONTRACT NUMBER

5b. GRANT NUMBER

5c. PROGRAM ELEMENT NUMBER

5d. PROJECT NUMBER

5e. TASK NUMBER

5f. WORK UNIT NUMBER

8. PERFORMING ORGANIZATION REPORT

ERDC/CRREL TR-03-12

10. SPONSOR / MONITOR'S ACRONYM(S)

11. SPONSOR / MONITOR'S REPORT NUMBER(S)

3701 Fairfax Drive

Arlington, VA 22203

12. DISTRIBUTION / AVAILABILITY STATEMENT

Approved for public release; distribution is unlimited.

Available from NTIS, Springfield, Virginia 22161.

13. SUPPLEMENTARY NOTES

\section{ABSTRACT}

Canine detection of buried landmines is thought to be an olfactory process and efforts are now underway to develop electronic sensing of explosives vapors. The quantity of these vapors is critical to any chemical-sensing-based procedure for detecting landmines. Plastic-cased mines release vapors of explosive-related compounds (ERC) by permeation through the casing as well as through holes and cracks. Measurement of permeation contributions to the release flux was reported previously for a few intact mines. Here we determine permeationdriven fluxes and diffusivities by analysis of ERC release into water as a function of time. The solubility of TNT and diffusivities of TNT, 2,4-DNT, and 1,3-DNB in five polymeric materials potentially used in mine casings are reported for the first time. This information can be used to estimate ERC fluxes from TNT-filled mines encased in any of these materials. Direct measurement of the release fluxes from intact mines are feasible and were described previously. Calculated diffusivities of the nitroaromatics in these materials were similar to those reported in the literature for other aromatic vapors. Diffusion was generally non-Fickian (concentration-dependent). TNT fluxes into Tedlar bags were also measured at 3,13 , and $22^{\circ} \mathrm{C}$ for the five materials. The temperature dependence is well described by simple exponential relations of the van't Hoff/Arrhenius type, and an activation energy was calculated for the process. The temperature dependence of the fluxes was similar for all five materials. Fluxes of individual ERC components were also determined at $22^{\circ} \mathrm{C}$ and reflected their abundance in the headspace of the source explosive. Plastic/air partition coefficients of the contaminants ranged from $1 \times 10^{3}$ to $3 \times 10^{5}$ and were about an order of magnitude higher for TNT than for DNB and were intermediate for DNT.

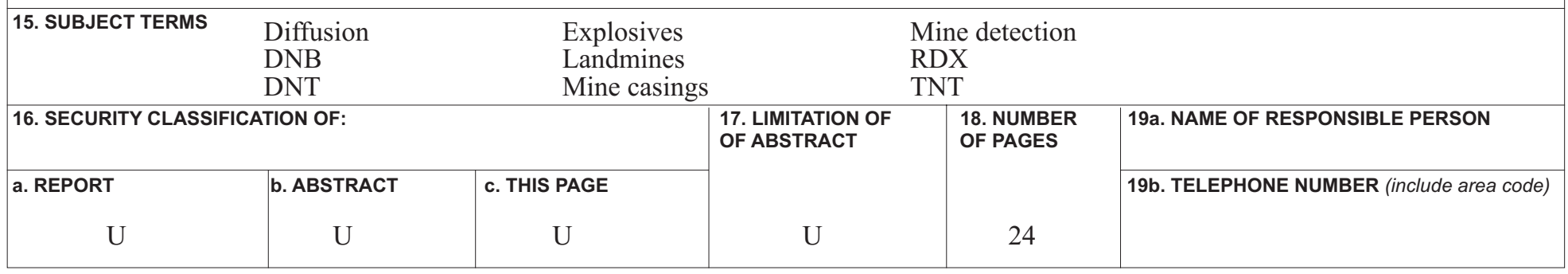

